Jpn. J. Pharm. Health Care Sci.
ノー ト 33(5) 451-456 (2007)

\title{
吸入流速値に基づく吸入デバイス選択の検討
}

\author{
坂野昌志 ${ }^{* 12}$, 間瀬広樹 ${ }^{2}$, 島田 泉 $^{2}$, 中村 桂 $^{1}$ \\ 名古屋セントラル病院薬斉科 1 \\ $\mathrm{NHO}$ 三重中央医療センター薬剤科 ${ }^{2}$
}

\section{Selecting Inhalation Devices Based on Inspiratory Flow Rate}

\author{
Masashi Banno*1,2, Hiroki Mase ${ }^{2}$, Izumi Shimada ${ }^{2}$ and Katsura Nakamura ${ }^{1}$ \\ Department of Pharmacy, Nagoya Central Hospital ${ }^{1}$ \\ Department of Pharmacy, Mie Chuo Medical Center ${ }^{2}$
}

$\left[\begin{array}{l}\text { Received October 10, 2006 } \\ \text { A ccepted February } 22 \text { 2007 }\end{array}\right]$

When the dry powder type inhalation steroid (DPI-ICS) device is selected, its suitability based on the inspiratory flow rate value is not checked for all patients. It was therefore considered necessary to establish standards for selecting inhalation devices. With this in mind, the relationship between the inspiratory flow rate and the device was investigated, and the application of this to the selection of inhalation devices was studied.

The subjects for this study were outpatients of the Mie Chuo Medical Center who were using DPI-ICS devices. The inspiratory flow rate was measured using an Incheck instrument and the suitability of devices was examined with an inhala tion tester.

Though $13.5 \%$ of the subjects using Diskus and $25 \%$ of those using Turbuhaler satisfied the mimimum requirement of $30 \mathrm{~L} / \mathrm{min}$, there was no reaction with the inhalation tester which suggested that inhalation might not be very good. However, inhalation was more effective when patients were given proper instruction on inhalation. Changing devices based on investigation of their suitability was also found to be effective.

In view of the above findings, we felt it necessary to develop a system for the prescribing of inhalers by doctors after pharmacists have investigated their suitability using the Incheck instrument and the inhalation tester. We have been trying out such a system.

Key words — inspiratory flow rate, Incheck, bronchial asthma, chronic obstructive pulmonary disease

\section{目的}

ドライパウダー式吸入ステロイド薬(DPI-ICS)は薬剂 の性質上 , デバイス内で乱気流を発生させる必要がある ためTurbuhaler, Diskusでは30 L/min 以上, Diskhaler においては $60 \mathrm{~L} / \mathrm{min}$ 以上の吸入流速が必要である ${ }^{1-5)}$. 日本のDPI-ICS は Turbuhaler, Diskus, Diskhaler の3種 類のデバイスがあるが, 必ずしも患者毎に吸入流速值を 基にしたデバイスの適正が調べられているわけではな ( ${ }^{6)}$, 吸入指導時に適切なデバイスが選択されていない と思われる症例を経験する . 治療を行う上で適切なデバ イスの選択は不可欠であり，デバイス選択の基準を設け ることが必要であると考える．

そこで今回，吸入流速とデバイスの関係を調査し薬剂 選択への応用について検討した .
方法

三重中央医療センター呼吸器科外来で吸入ステロイド 薬を使用している男性 78 人, 女性 57 人を対象にイン チェック ${ }^{\circledR}$ (CLEMENT CLARKE 社製)で吸入流速を測定

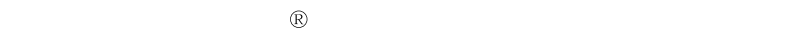
スに対応するアダプターをつけた上で, 使用説明書に従 い3 回測定を行い平均值を求めた . 対象患者の使用デバ イスは, Turbuhaler が 36 人, Diskusが 111 人の 135 人， 147 症例(Budesonine-Turbuhaler ${ }^{\circledR}(($ 株)アストラゼネカ)と salemeterol-Discus ${ }^{\circledR}($ (株)グラクソ・スミスクライン)併用 患者が 12 人であったため)であったため発音によって吸 入適性か確認できる Turbuhaler Trainer, Diskus Trainer(以 下, 吸入テスターと略す)もインチェック ${ }^{\circledR}$ 同樣に 3 回吸 入させて反応の有無について調査した . 調査終了後には 
インチェック ${ }^{\circledR}$ と吸入テスターの結果について説明しな がら吸入指導を実施した . 調査によって使用中のデバイ スでは効果的な吸入ができないと考えられた患者は吸入 流速に基づきデバイスが変更された .デバイス変更の効 果は, 変更前と変更後 3 力月時点の Forced expiratory volume in one second(FEV 1.0), Peak expiratory flow rate (PEF) の比較で検討した . また，三重中央医療センター で採用している定量噴霧式吸入薬(PMDI)は Hydrofluoroalukan-beclomethasone dipropionate(HFA-BDP) のみであるため末梢の呼吸機能の変化も指標とする必要 があると考え゙), Maximum expiratory flow rates at 50\%(V 50), Maximum expiratory flow rates at $25 \%$ (V 25)での検討 も行った . 判定方法は FEV 1.0, PEF のいずれかが 12\% 以上もしくはFEV 1.0 が $200 \mathrm{~mL}$ 以上改善している場合 を改善とした ${ }^{8)}$. また , FEV 1.0, PEF のいずれかが 12\% 以上もしくはFEV 1.0 が $200 \mathrm{~mL}$ に満たない程度の改善 が認められた場合を不変, デバイス変更等により FEV 1.0, PEF 等が低下した場合を悪化とした .

また，吸入流速と呼吸機能検査値の関係についての報 告されている内容りとの相関を調べるために, デバイス ごとに求めた吸入流速值と FEV 1.0, PEF との関連性に ついて検討した . 吸入流速と呼吸機能検査值の関連性は ピアソンの相関係数検定を用いて検討を行い有意水準 5 \%以下として評価した .

複数のDPI デバイスを併用している患者では, 弚れ

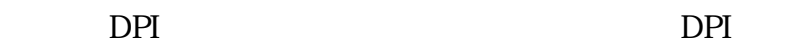
イスの比較についても検討した .
結果

吸入流速はTurbuhaler が58.1+ 15.6 L/min, Diskusが 82.3 29.5L/min であった(Table 1). また, 吸入流速平 均を求めるための 3 回の測定中 , $5 \mathrm{~L} / \mathrm{min}$ 以上の誤差を 生じた症例はなかった .

Turbuhaler 使用患者の $25 \%$ (9人/36人)と Diskus使用 患者の $13.5 \%$ (15人/111人)は両剂を吸入する際に必要 な最低吸入流速である $30 \mathrm{~L} / \mathrm{min}$ 以上であったが吸入テ スターの反応がなくうまく吸入できていない可能性が考 えられた .jまく吸入できていない可能性が考えられた 24 人中，8人は吸入指導によって吸入流速の増加と吸入 テスターの反応が認められた(Fig.1) . このうち, 呼吸機 能検査值は, 死亡 1 人, 他院への変更 3 人を除く 4 人全 員が改善した(Fig.2) . 吸入指導でも改善しなかった患者

Table 1 . Patient Background.

\begin{tabular}{l|c} 
Sex (M:F) & $78: 57$ \\
\hline Age(range) & $60.4(28-82)$ \\
\hline Mean FEV1.0(L/sec) & $1.73 \pm 0.86$ \\
\hline Mean FEV1.0\% & $63.7 \pm 15.6$ \\
\hline Mean PEF(L/sec) & $4.06 \pm 2.31$ \\
\hline $\begin{array}{l}\text { The inspiratory flow rate of } \\
\text { Turbuhaler. (L/min) }\end{array}$ & $58.1 \pm 15.6$ \\
\hline $\begin{array}{l}\text { The inspiratory flow rate of Diskus. } \\
\text { (L/min) }\end{array}$ & $82.3 \pm 29.5$ \\
\hline \multicolumn{2}{|c}{ (mean \pm S.D.) }
\end{tabular}

\begin{tabular}{l|l}
$\begin{array}{l}\text { Bronchial Asthma Stage } \\
\text { step 2 }\end{array}$ & 38 \\
\hline step 3 & 73 \\
\hline step 4 & 24
\end{tabular}

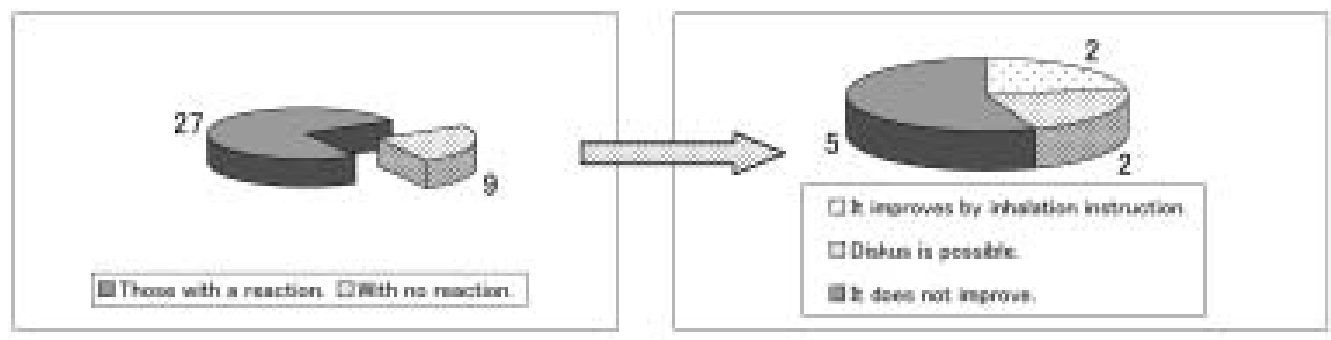

Turbuhaler : Inhalaton-tester unreacted case, Turbuhaler : Correspondence to an Inhalaton-tester unreacted case. All numbers are numbers of patients.

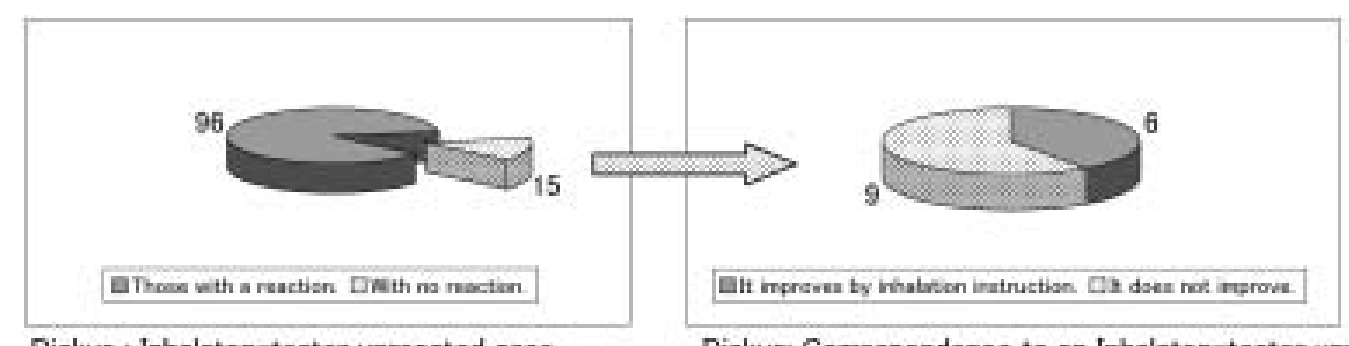

Diskus : Inhalaton-tester unreacted case.

Diskus: Comespandence to an Inhalaton-tester urreacted case. All numbers are numbers of patients.

Fig .1. The Effect of Inhalation Instruction. 
16 人のうち死亡 2 人, 他院への変更 2 人, 変更拒否 1 人を除く 11 人に対してデバイス変更が行われた . デバ イス変更は Turbuhaler から HFA-BDPへが4人, Discus

The improvement patient by instruction.(FEV1.0) (L/sec)

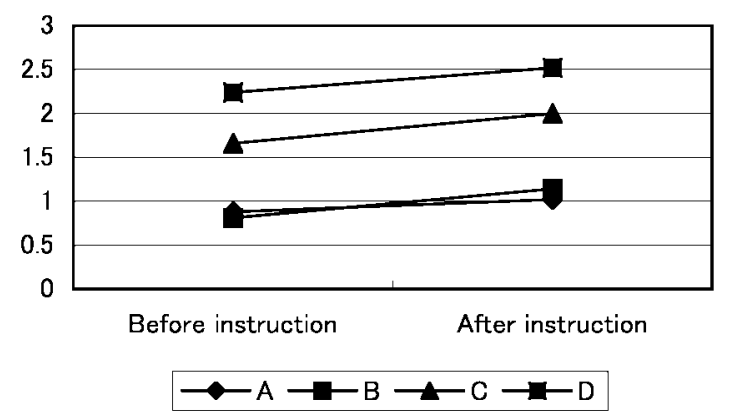

から HFA-BDPへが 6 人 , T urbuhaler から Diskusへが 1 人で, 呼吸機能検査值は 8 人が改善し, 3 人は不変で, 悪化した症例はなかった(Fig.3) .

$$
(\mathrm{L} / \mathrm{sec})
$$

The improvement patient by instruction.(PEF)
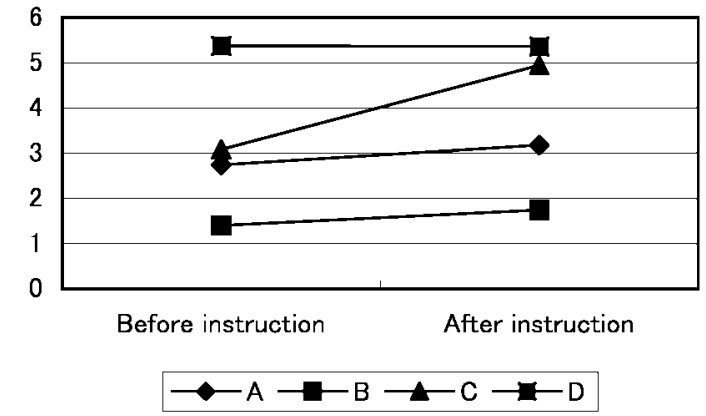

Fig 2. The Respiratory Function Test Value Change of the Inhalation Flow Rate Improvement Patient by Instruction.

Change of FEV1.0

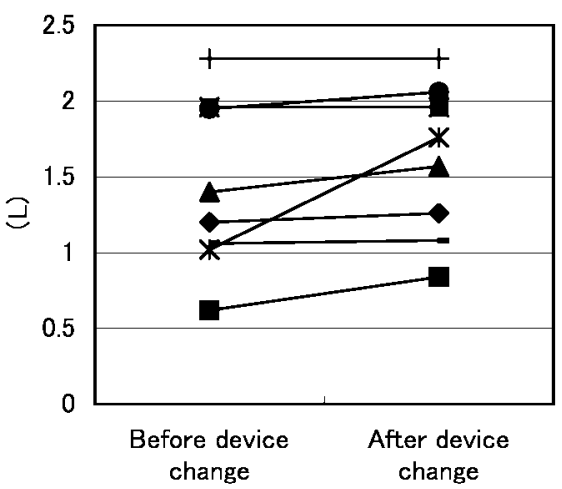

Change of $\mathrm{V} 25$

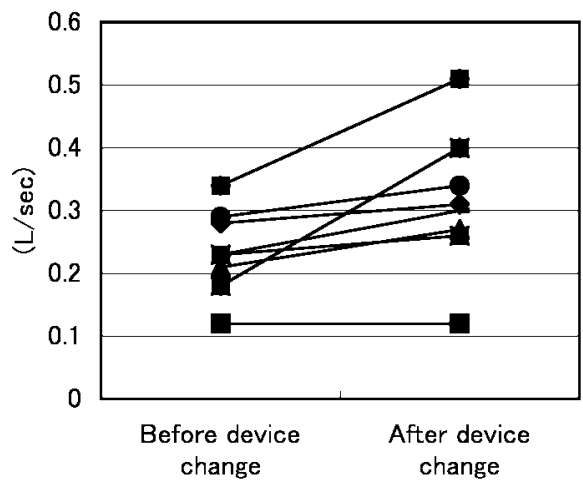

Change of PEF

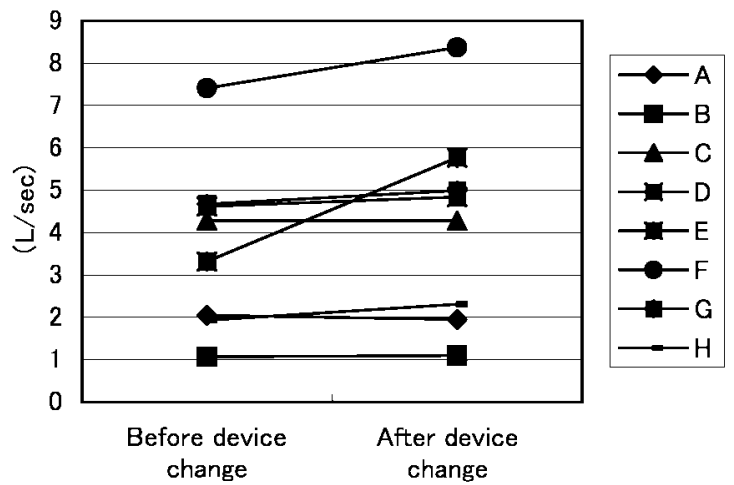

Change of V50

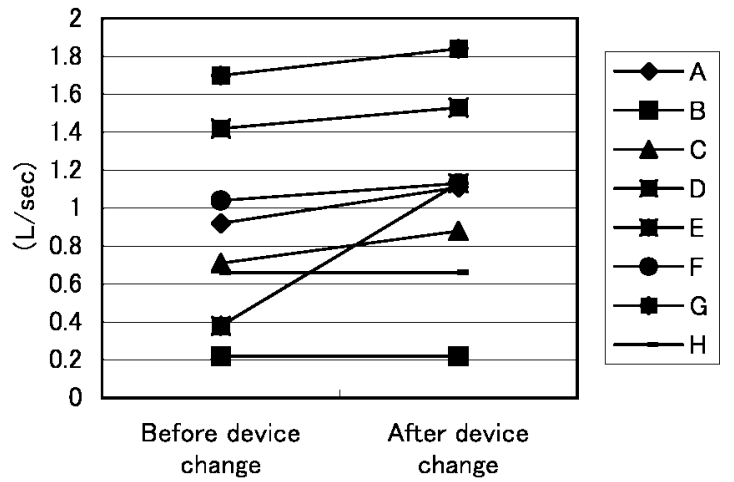

The content of device change.

\begin{tabular}{|l|c|c|c|c|c|c|c|c|}
\hline $\begin{array}{l}\text { Patient } \\
\text { number }\end{array}$ & $A$ & $B$ & $C$ & $D$ & $E$ & $F$ & $G$ & $H$ \\
\hline device & $\mathrm{T} \rightarrow \mathrm{H}$ & $\mathrm{D} \rightarrow \mathrm{H}$ & $\mathrm{T} \rightarrow \mathrm{H}$ & $\mathrm{D} \rightarrow \mathrm{H}$ & $\mathrm{D} \rightarrow \mathrm{H}$ & $\mathrm{T} \rightarrow \mathrm{H}$ & $\mathrm{D} \rightarrow \mathrm{H}$ & $\mathrm{T} \rightarrow \mathrm{D}$ \\
\hline
\end{tabular}

Fig 3. A Device Change Effective Patient's Respiratory Function Test V alue Change. 
呼吸機能検査値と吸入流速の関係では, FEV 1.0 と Turbuhaler 吸入流速との相関関係は $p=0.05 r=0.49$ で,

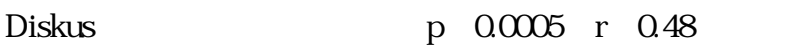
た.PEFではT Turbuhaler 吸入流速およびDiskus吸入流 速の相関関係は Turbuhaler : $p=0.004 r=0.67$, Diskus : $p$ $=1.04 \times 10-7 r=0.51$ となり，これまでに報告されてい る内容と同樣に呼吸機能検査值の中で最も高い相関性を 示した(Fig.4) .

デバイスの比較では Turbuhaler と Diskus 併用患者 12 人の吸入流速平均值から Turbuhaler に Diskus $の 1.42$ 倍 の吸入抵抗を認めた(Table 2) . 兴こで, Diskus使用患者 のうち吸入流速が55 100 L/min の患者 53 人に Turbuhaler の吸入テスターと Turbuhaler のアダプターを着け たインチェックでの調査を行ったところ，吸入流速が 55 70 L/min 以下の患者の $33 \%(7 / 21$ 人)でTurbuhaler の吸入テスターでは反応か認められず吸入流速は $50 \mathrm{~L} /$ min 以下になった .

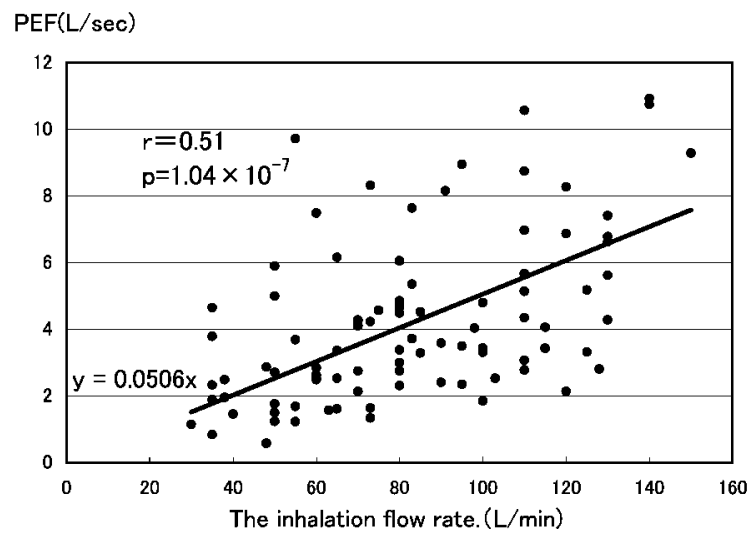

Fig :41. Relation between the Diskus Inspiratory Flow rate and PEF.

$$
\text { 考察 }
$$

DPI-ICS は吸入手技の簡便性および吸入効率の良さか ら第一選択薬として選ばれるようになっている(Global Initiative for A sthma Pocket Guide, http ://www.sma.org/ sdi / articles/asthma_pediatrics_pocket_guide.pdf \# search = ' POCKET \% 20 GUIDE \% 20 FOR \% 20 A STHMA' Global Initiative For Asthma, 2004, pp.16-17.). しかし，今回 の調査結果より，DPI 使用中の外来患者では 16\%(24) 147)と多くの患者がうまく吸入できていない可能性があ ることがわかった .このうち 8 人は吸入指導によって呼 吸機能検查值か改善していることから，吸入指導を正し く理解した薬斉師による適切な吸入指導の重要性を改め て認識した .

日本で発売されているDPI-ICSのうち，T Turbuhaler と Diskusは吸入流速が $30 \mathrm{~L} / \mathrm{min}$ 以上の吸入流速で吸入で きるといわれている.吸入テスターも Turbuhaler では 35 $\pm 5 \mathrm{~L} / \mathrm{min}$ ，Diskusでは $30 \mathrm{~L} / \mathrm{min}$ で反応するように設定 されているため吸入流速が $40 \mathrm{~L} / \mathrm{min}$ 以上であれば吸入

$\operatorname{PEF}(\mathrm{L} / \mathrm{sec})$

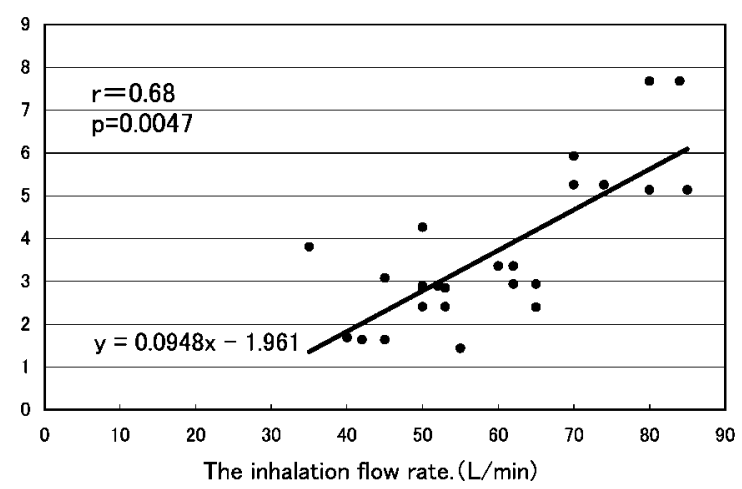

Fig 4-2. Relation between the Turbuhaler Inspira tory Flow Rate and PEF.

Table 2. Discus, a Turbuhaler Concomitant Use Patient's Inhalation Flow Rate Comparison.

\begin{tabular}{|c|c|c|c|c|c|c|c|}
\hline $\begin{array}{c}\text { sex } \\
\text { (Age) }\end{array}$ & device & $\begin{array}{c}\text { Incheck } \\
\text { Data }\end{array}$ & $\mathrm{D} / \mathrm{T}$ & $\begin{array}{c}\text { sex } \\
\text { (Age) }\end{array}$ & device & $\begin{array}{c}\text { Incheck } \\
\text { Data }\end{array}$ & $\mathrm{D} / \mathrm{T}$ \\
\hline \multirow{2}{*}{$\begin{array}{l}M \\
74 \\
\end{array}$} & $\mathrm{D}$ & 110 & \multirow[t]{2}{*}{1.3} & \multirow{2}{*}{$\begin{array}{c}F \\
80 \\
\end{array}$} & $\mathrm{D}$ & 73 & \multirow[t]{2}{*}{1.6} \\
\hline & $T$ & 85 & & & $T$ & 45 & \\
\hline \multirow{2}{*}{$\begin{array}{l}M \\
78\end{array}$} & $\mathrm{D}$ & 90 & \multirow[t]{2}{*}{1.8} & \multirow{2}{*}{$\begin{array}{l}M \\
74\end{array}$} & $\mathrm{D}$ & 85 & \multirow[t]{2}{*}{1.1} \\
\hline & $\mathrm{T}$ & 50 & & & $T$ & 80 & \\
\hline \multirow{2}{*}{$\begin{array}{l}M \\
34\end{array}$} & D & 100 & \multirow[t]{2}{*}{1.3} & \multirow{2}{*}{$\begin{array}{l}\mathrm{F} \\
60\end{array}$} & D & 110 & \multirow[t]{2}{*}{1.6} \\
\hline & $T$ & 80 & & & $T$ & 70 & \\
\hline \multirow{2}{*}{$\begin{array}{l}M \\
69 \\
\end{array}$} & $\mathrm{D}$ & 65 & \multirow[t]{2}{*}{1.3} & \multirow{2}{*}{$\begin{array}{l}M \\
73 \\
\end{array}$} & $\mathrm{D}$ & 100 & \multirow[t]{2}{*}{1.3} \\
\hline & $T$ & 50 & & & $T$ & 75 & \\
\hline \multirow{2}{*}{$\begin{array}{l}M \\
77 \\
\end{array}$} & $\mathrm{D}$ & 80 & \multirow[t]{2}{*}{1.5} & \multirow{2}{*}{$\begin{array}{l}F \\
78\end{array}$} & $\mathrm{D}$ & 50 & \multirow[t]{2}{*}{1.7} \\
\hline & $T$ & 55 & & & $T$ & 30 & \\
\hline \multirow{2}{*}{$\begin{array}{l}F \\
56\end{array}$} & $\mathrm{D}$ & 83 & \multirow[t]{2}{*}{1.3} & \multirow{2}{*}{$\begin{array}{l}M \\
75\end{array}$} & $\mathrm{D}$ & 55 & \multirow[t]{2}{*}{1.4} \\
\hline & $T$ & 65 & & & $T$ & 40 & \\
\hline
\end{tabular}

T:Turbuhaler ${ }^{\circledR}$ D:Discus $\otimes$

D/T:Incheck Discus ${ }^{\circledR}$ Data/Incheck Turbuhaler ${ }^{\circledR}$ Data 
テスターの反応は得られるはずである．しかし，吸入流 速が 40 50 L/min の患者でも吸入テスターの反応が認 められなかったことから，吸入流速が50 L/min 以上な いとうまく吸入できない可能性が考えられる .

吸入指導を行っても吸入流速の改善か認められず，デ バイスの変更が行われた患者 11 人中 8 人で呼吸機能検 査值の改善か認められ，呼吸機能検査値で $30 \%$ 以上の 改善を認めた症例の存在などからデバイス適正の確認は 必須であると考える. また, DPI-ICS の吸入残渣の改善 に複数回吸入する手技か報告されている ${ }^{10}$. 最低限必要 な吸入流速以上での繰り返し吸入は有効であることは間 違いない，しかし, 治療に必要な吸入流速が得られない 患者では複数回吸入しても十分な効果が得られない可能 性も考えられる. 弚のためDPI-ICS 導入時からの効果的 な使用を考えるならデバイス適正を確認した後での処方 を徹底する必要があると考える．

吸入流速と呼吸機能検査値の関係は, PEF で $2 \mathrm{~L} / \mathrm{sec}$ 以下の場合は吸入流速が必要量に満たなかった症例を多 く認めたため, PEF が $2 \mathrm{~L} / \mathrm{sec}$ 以下の呼吸機能が低下し た患者へのDPI の選択は特に注意が必要だと考える． しかし, 呼吸機能検査からだけでは吸入できるかの確実 な判断ができないため,やはり，デバイス適正を確認し た後での処方を徹底する必要があると考える．

デバイスの比較では, Turbuhaler は Diskusよりも吸入 抵抗が高いことが in vitro 試験で報告されている11) 。 かし，T Turbuhaler は薬剂量が少なく，操作が簡単なため 高齢て呼吸機能が低下した患者には使いやすいと考えら れていたが，今回の調査結果から，Turbuhaler は Disku の平均 1.42 倍の吸入抵抗を認めた . この数值は報告さ
れている内容 ${ }^{11} と$ 同程度であり臨床においても同樣の結 果であった . 产のため早い吸入流速が得られにくい呼吸 機能が低下した患者には吸入しにくいデバイスである可 能性が示唆された .

成人喘息患者に対するICSの第一選択はDPI である が，吸入抵抗をもとに考えれば確実な吸入を得るために Diskusを選択した方がよいと考える. 兴の後, 副作用 等の問題があった場合に Turbuhalerへの切り替えを検討 し，呼吸機能が低下した患者では吸入抵抗を生じない PMDI の選択を考慮する必要があると考える．また， Diskusのみを使用している患者のうち，T Turbuhaler はう まく吸入できない可能性がある患者が $7 \%(7 / 96)$ 存在す ることや，PEFで $2 \mathrm{~L} / \mathrm{sec}$ 以下の患者は慎重なデバイス 選択の必要が考えられることからも，インチェック ${ }^{\circledR} お$ よび吸入テスターでデバイスの適性を確認した後に処方 するシステムを確立する必要があると考える．乥れは， 薬剂に対する知識や操作上の問題点も含めたデバイスに 対する知識を持ち，患者の声を受け止めることができる のは薬剂師だけであると考えるからである．

今回の指導やデバイス変更による呼吸機能改善という

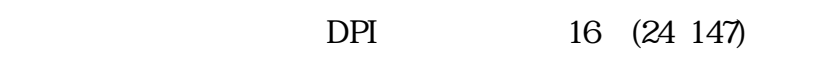
まく吸入できていない可能性があつた原因は, 完全に理 解されないまま指導を終えた医療者側の不適切な吸入指 導や適正なデバイスであるかを確認していなかったこと が原因であると考える．兰こで，処方前に適正なデバイ スを確認する必要があると考え, 三重中央医療センター では, 薬闵師が適正なデバイスを選択した後に医師が吸 入薬を処方するシステムを試行している(Fig.5) . また， 吸入指導方法についても地域の薬剂師会と協議を行い講

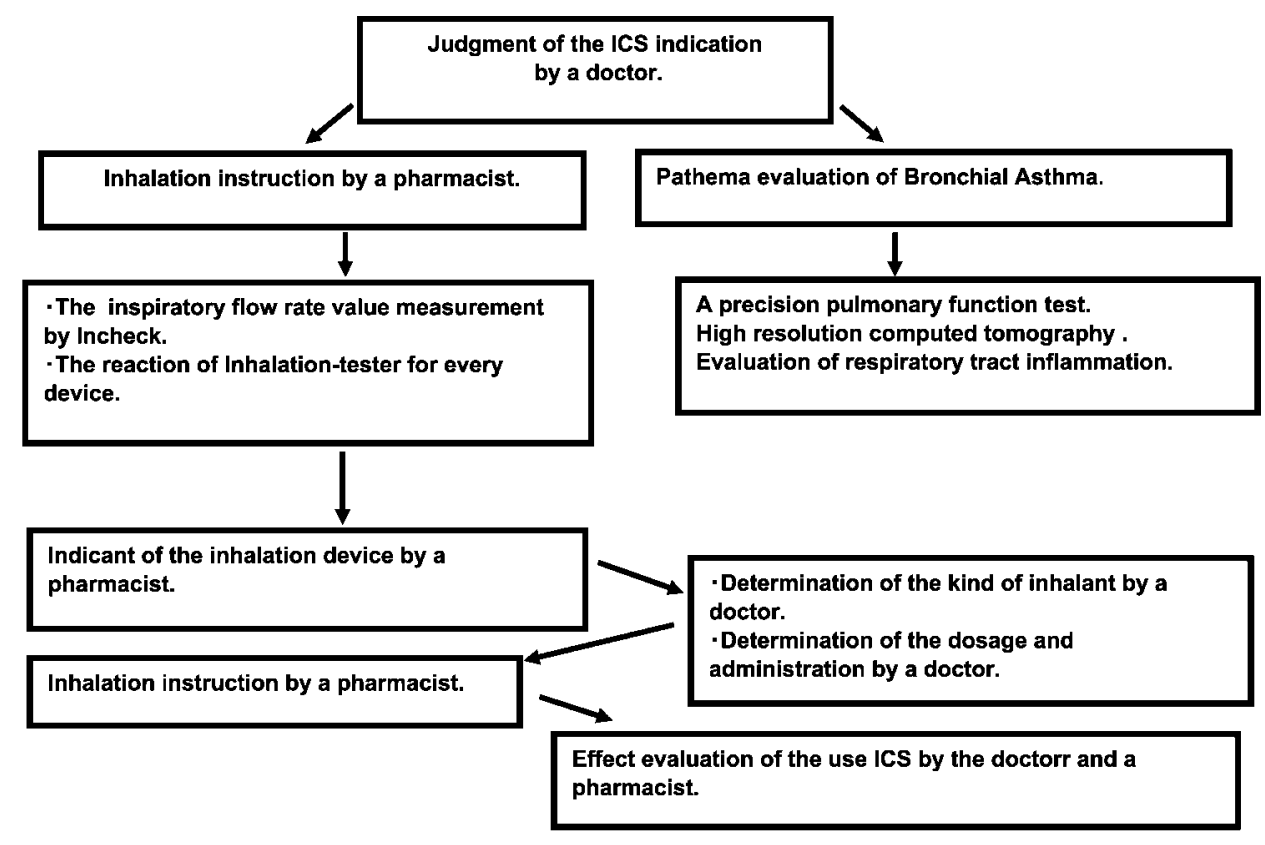

Fig .5. The Trial of the ICS Selection by Mie Chuo Medical Center. 
習会や勉強会を開き啓蒙活動を行っている．

今後はさらにデバイス増加が見込まれるため，一層デ バイスの適正判断が重要になる .光こで, 本システムの問 題点の抽出ならびに改善を行いながら，より良いシステ ムへと発展させる必要があると考える . 同時にデバイス を有する他の薬剂においても薬剂師が積極的に適性判断 に加わり, 適切なデバイス選択を通じて薬物療法に寄与 することが今後の業務において必要であると考えている．

\section{引用文献}

1) S. Pedersen, O.R. Hansen, G. Fuglsang, Influence of inspiratory flow rate upon the effect of a Turbuhaler, Archives of Disease in Childhood, 65, 308-319 (1990).

2) A. Malton, B.S. Sumby, I.J. Smith, A comparison of in vitro drug delivery from two multidose powder inhala tion devices, European Journal of Clinical Research, 7, 177-193 (1995).

3) A. Brindley, B.S. Sumby, I.J. Smith, D. Prime, P.A. Haywood, A.C. Gant, Design Manufacture and Dose Consistency of the Serevent Diskus Inhaler,Pharmaceutical Technology Europe, JANUARY, 14-22(1995).

4) Hartwig Steckel, W. Bernd, In vitro evaluation of dry powder inhalers I : drug desposition of commonly used devices, international journal of pharmaceutics, 154, 19-29 (1997).

5) D. Prime, P.J. Atkins, A. Slater, B. Sumby, Review of dry powder inhalers, Advanced Drug Delivery Reviews, 26, 51-58 (1997).

6) H. Ohbayashi, H. Yamase, An evalution of the acceptance of budesonide turbuhaler by older japanese pa tients with bronchial asthma when changed from fluticasone propionate(FP) or beclomethasone dipropionate (BDP), Jpn. J. Allergol, 52, 39-42 (2003).

7) H. Ohbayashi, The small airway inflamma of athmatic patients who have used dry powder type inhaled steroid for moderatelong term evaluated by induced sputum and the efficancy of HFA-BDP(QVARTM) inhalation, Jpn. J. Allergol, 54, 24-35 (2005).

8) 日本呼吸器学会肺生理専門委員会“, 呼吸機能検査力゙ イドライン”,メディカルレビュー社, 東京, 2004. pp.12-23.

9) H. Tanaka, M. Hashimoto, S. Sahara, T. Ohnishi, M. Fujii, K. Suzuki, T. Saikai, S. A be, Pathological and ra diological approach to the small airway disease in asthma: Limitation of current inhamed corticosteroid therapy, Allergology International, 53, 1-6 (2004).

10) H. Yamashita, Y. Ohta, T. Kawakatsu, Y. U eda, Evaluation of Dry Powder Steroid Inhaler in Instruction on the Use, Jpn. J. Pharm. Health Care Sci., 28, 456-460 (2002).

11) M.E.A.C. Broeders, J. Molema, N.A. V ermue, H.Th.M. Folgering, Peak inspiratory flow rate and slope of the inhalation profiles in dry powder inhalers, European Respiratory Journal , 18, 780-783 (2001). 